\title{
Les chansons des Nganassans
}

The songs of the Nganassan

Nganassanide laulud

ПЕСНИ НГАНАСАН

\section{Oksana Dobžanskaja}

Traducteur : Eva Toulouze

\section{OpenEdition}

\section{Journals}

Édition électronique

URL : https://journals.openedition.org/efo/5011

DOI : $10.4000 /$ efo. 5011

ISSN : 2275-1947

Éditeur

INALCO

Édition imprimée

ISBN : 978-2-343-08571-5

ISSN : 0071-2051

\section{Référence électronique}

Oksana Dobžanskaja, «Les chansons des Nganassans », Études finno-ougriennes [En ligne], 47 | 2015, mis en ligne le 13 juillet 2016, consulté le 20 septembre 2021. URL : http://journals.openedition.org/ efo/5011 ; DOI : https://doi.org/10.4000/efo.5011

Ce document a été généré automatiquement le 20 septembre 2021.

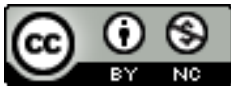

Études finno-ougriennes est mis à disposition selon les termes de la Licence Creative Commons Attribution - Pas d'Utilisation Commerciale 4.0 International. 


\section{Les chansons des Nganassans}

The songs of the Nganassan

Nganassanide laulud

ПЕСНИ НГАНАСАН

Oksana Dobžanskaja

Traduction : Eva Toulouze

\section{NOTE DE L'AUTEUR}

Cet article a été mis au point dans le cadre du projet $N^{\circ} 14-38-00031$ «Constitution d'un laboratoire de recherches géoculturelles complexes dans l'Arctique » du Fonds russe pour la recherche.

\section{Un bref aperçu de l'étude du folklore nganassan}

1 Dans cet article, je présente au lecteur le folklore chanté des Nganassans, ce phénomène unique dans la culture musicale du monde.

2 Les Nganassans vivent dans la péninsule du Tajmyr et font partie des « petits peuples » autochtones de la Fédération de Russie (ils sont 847 , d'après les chiffres du recensement de 2010). Ils parlent une langue samoyède. La riche culture nganassane, une culture de chasseurs, éleveurs de rennes, pêcheurs - a conservé des traits de l'ancienne culture des chasseurs de rennes sauvages (Simchenko 1976) et a été étudiée par plusieurs générations de chercheurs de Russie.

3 La collecte, l'étude et la publication des genres de chants de l'oralité nganassane ont été lancées il y a relativement peu de temps, dans le dernier quart $\mathrm{du} \mathrm{xx}^{\mathrm{e}}$ siècle. Plusieurs chercheurs ont publié des textes collectés: les folkloristes N.T. Kosterkina, K.I. Labanauskas, le linguiste E.A. Helimski ; les linguistes V.Ju. Gusev et M.M. Brykina pont travaillé à déchiffrer les textes. D'autres ont réalisé et publié des transcriptions musicales des chants nganassanes : l'auteur de cet article, T. Ojamaa, L. Leisjö. Nous 
disposons aussi de notations de terrain d'I.A. Brodskij, Ju.I. Šejkin, V.S. Nikiforova. Les sources dans lesquelles on peut trouver des échantillons de chants nganassans ne sont pas nombreuses (Helimski 1989 ; Labanauskas 1992 ; Dobžanskaya, Kosterkina 1995).

4 Les phénomènes critiques contemporains qui ont un effet négatif sur la culture traditionnelle des Nganassans dans son ensemble se reflètent également sur l'état de la pratique des chants. Le chant est un phénomène de plus en plus rare dans la vie des Nganassans, avec la disparation des situations de vie qui donnaient naissance aux chants personnels, aux chants pour enfants, aux chants métaphoriques et aux chants chamaniques (déplacements en traîneau, raccommodage des filets, confection des vêtements traditionnels, contacts avec les invités, conversations traditionnelles métaphoriques, rituels chamaniques, etc.).

5 Le recueil «Chants et chanteurs de la toundra d'Avam» est la collection la plus complète du folklore musical des Nganassans à ce jour.

6 Dans la mesure où il n'existe pratiquement pas de nouvelles compositions, les collections existantes et les matériaux collectés à la fin $\mathrm{du} \mathrm{xx}^{\mathrm{e}}$ siècle jouent un rôle central pour la connaissance de ces formes de créativité populaire : les chants doivent être publiés et analysés scientifiquement. Cet article est né pour répondre au désir de faire connaître à un large cercle de lecteurs les matériaux présentés dans le recueil de folklore musical nganassan intitulé "Chants et chanteurs de la toundra d'Avam", publié à Noril'sk en 2014 avec le soutien de la filiale polaire de l'entreprise «GMK Noril'skij nikel'1 $"$ (Dobžanskaya 2014).

7 Ce recueil contient les chants nganassans recueillis dans les villages d'Ust' Avam et de Voločanka par des chercheurs de différentes disciplines: des musicologues comme Ju.I. Šejnik, V.S. Nikiforova et O.E. Dobžanskaja entre 1986 et 2006, des linguistes comme E.A. Helimskij dans les années 1980 et 1990, V.Ju Gusev et M.M. Brykina en 2005, et le folkloriste français Jean-Luc Lambert en 1997.

Le recueil contient cinquante échantillons de musique nganassane avec les transcriptions musicales et les textes en nganassan et en russe. Plus précisément y sont représentés douze chants métaphoriques kejngejrsja ${ }^{2}$, sept chants personnels baly ${ }^{3}$, cinq chansons à boire hoangkuju baly ${ }^{4}$, six chants d'enfants njuo baly ${ }^{5}$, deux berceuses, sept chants chamaniques ngaza baly ${ }^{6}$, six chants extraits de contes sitaby baly ${ }^{7}$, ainsi que des imitations de voix d'animaux.

9 Ces chants ont été collectés auprès de chanteurs remarquables: Tubjaku Djuhodovič Kosterkin (1921-1989), Ekaterina Subobteevna Kosterkina (1940-2009), Numumu Hursapteevič Turdagin (1904-1993) du village d'Ust' Avam; et Valentina Bintaleevna Kosterkina, (1938-1998), Den'čude Nuteevič Mirnyh (1923-2006), Salir Mydovič Porbin (1920-2001), Neljutasi Fominična Porbina (1922-2002), Syku Modjureevna Jarockaja (1939), Faina Lambakovna Jarockaja (1940) du village de Voločanka.

\section{La segmentation du folklore musical des Nganassans en genres}

10 Avant de parler des chants proprement dits, il convient de déterminer les frontières des genres des chants nganassans, qui reposent sur la différenciation des fonctions jouées par chacun d'entre eux dans la culture nganassane. 
11 À mon avis, il convient d'extrapoler à la culture musicale nganassane la distinction fondamentale des genres, acceptée depuis la Grèce antique, en "épopée ", "chant lyrique » et "drame» (rituel). Cette segmentation a été à maintes reprises et avec succès acceptée par les folkloristes, les ethnographes et les musicologues pour l'étude de la culture nénetse, qui est tout à fait proche de la culture des Nganassans. Ainsi, les chants nénetses ont été catégorisés comme " épiques », « lyriques » et « rituels » (c'està-dire chamaniques) (Kuprijanova 1960, p. 17-19; Homič 1995, p. 259-261 ; Niemi 2004, p. 20-22). Dans la culture des Nganassans et des Nénetses, cette segmentation se confirme non seulement dans une perspective fonctionnelle, mais aussi du point de vue $\mathrm{du}$ style musical (ce qui veut dire que les genres s'opposent du point de vue des types d'intonation). Dans un rituel chamanique, le chant est collectif (polyphonie hétérophone) et accompagne des instruments produisant du son (tambour, pendentifs du costume chamanique, etc.), avec l'usage d'onomatopées (signaux imitatifs et cris de bergers). Le chant, dans l'épopée et dans les genres chantés, est toujours à une voix et n'est pas accompagné d'instruments musicaux, il comporte une intonation vocale ou vocalo-discursive de solo. Mais le chant épique et les autres chants eux aussi se distinguent par le type d'intonation : dans les chants ordinaires, la préférence va à une intonation vocale, alors que les récits épiques sont construits sur une alternance d'intonations discursives et discursivo-vocales (Dobžanskaja 2008, p. 93-94).

Dans cet article, nous allons nous concentrer sur les genres chantés du folklore nganassan (plus précisément sur les dialogues métaphoriques, les chants personnels, les chants enfantins et les berceuses) que nous allons étudier sur la base d'exemples précis.

\section{Les chants nganassanes}

\section{Les chants métaphoriques}

Les dialogues métaphoriques chantés représentent un genre unique du folklore nganassan :

L'appellation nganassane de ce genre est kəjyəjśa ou kəjyəjrūa, ce qu'on peut traduire par "chant d'une personne à l'autre ", ou " concours de chant " (kajpəjr est une forme à sens réflexif issue de la base verbale kajyə - "chanter"). (Helimski 1989, p. 52)

Plusieurs chercheurs ont mentionné les caractéristiques de ce genre inimitable, le kajngalar métaphorique, forme de communication parmi les jeunes et les vieillards: c'est le cas des ethnographes B.O. Dolgih et L.A. Fajnberg dans leur article "Les Nganassans du Tajmyr » (Dolgikh, Fainberg 1960) ainsi que Ju.B. Simčenko dans son article « La fête Any'o-djaly chez les Nganassans de l'Avam » (Simčenko 1963).

C'est une langue dans laquelle parlent et plaisantent les jeunes garçons et filles, dans laquelle ils organisent des concours de chants enjoués et spirituels. Parfois aussi les vieillards utilisent entre eux la langue du kajngalar pour raconter comment ils sont allés en visite, à la chasse, à la pêche, etc. Il arrive même que les vieillards chantent en chœur dans cette langue des chants d'amour, qu'ils racontent comment ils faisaient la cour aux jeunes filles... Alors les jeunes, même s'ils comprennent les paroles, ne comprennent pas toujours leur sens caché. (Dolgikh, Fajnberg 1960, p. 55) 


$$
\text { catégories de Nganassans entre qui la communication était interdite (surtout entre }
$$
jeunes de sexes différents).

\begin{abstract}
Métaphoriques, fixés, les textes offrent au chanteur une certaine liberté d'expression. Les anciens Nganassans apprenaient à leurs enfants avant l'âge nuptial (vers les 17 ans) le langage «secret» du kejngejrsja. Dans ces chants, les paroles sont chiffrées à l'aide de substitutions lexicales, d'emprunts, d'archaïsmes, de formes tronquées de lexique courant. Le contenu du texte kejngejrsja est fabulisé, la réalité est décrite par images métaphoriques. (Dobžanskaya, Kosterkina 1995, p. 9-10).
\end{abstract}

Par exemple,

[...] le désir de demander une jeune fille en mariage est exprimé par l'intention de prendre sur le remorqueur un traîneau en sapin; ... la situation de trois prétendants pour une fiancée est comparée à la destinée de trois poissons, dont un, le plus alerte, va s'installer dans un cours d'eau où l'eau est pure, alors que les deux autres, moins débrouillards, sont contraints de se contenter d'eaux plus troubles ; ... les pitoyables efforts pour rivaliser avec la profondeur des pensées de l'un des maîtres incontestés de la métaphore peuvent être comparés aux tentatives d'un petit chien pour traverser en rampant une immense étendue de toundra, etc. (Helimskij 1989, p. 56-57)

La spécificité de la langue du kejngejrsja, comme le montre Helimskij dans son article «La syllabisation du vers dans les chants métaphoriques nganassans", tient à l'utilisation du chiffrage à trois niveaux de la structure du texte : niveau du sujet (elle se manifeste dans l'utilisation de l'allégorie et la fabulisation du contenu), niveau du lexique et de la morphologie (avec le remplacement de termes généralement utilisés par d'autres destinés à être utilisés exclusivement dans ce type de chant), niveau de la phonétique et de la syllabe (la règle est la permutation des syllabes aussi bien à l'intérieur des lexèmes que dans l'ensemble du vers chanté) (Helimskij 1989, p. 56-57, p. 72-74). L'utilisation conjointe de ces méthodes de chiffrage dans une œuvre était la norme ; de plus, c'est sur la base de ces critères que les Nganassans évaluent la qualité de la métaphore chantée.

Les échantillons de chants-kejngejrsja de ce recueil ont été exécutés par Salir Mydovič Porbin, Neljutasi Fominična Porbina, Valentina Bintaleevna Kosterkina, Tubjaku Djuhodovič Kosterkin, Ekaterina Subobteevna Kosterkina, Den'čude Neteevič Mirnyx, Syku Modjureevna Jarockaja. Nous allons examiner deux échantillons de ce type de chants, qui jusqu'ici n'ont pas attiré l'attention des chercheurs.

19 Le dialogue métaphorique exécuté par Valentina Bintaleevna Kosterkina et Den'čude Neteevič Mirnyx (exemple 1) représente la forme la plus rare, aujourd'hui pratiquement disparue, de dialogue métaphorique chanté. Deux chanteurs échangent questions-devinettes et réponses-solutions, chacun chantant sur sa propre mélodie en utilisant ses outils poétiques préférés.

20 Ce dialogue métaphorique kejngejrsja a été enregistré en 1996 à Dudinka, pendant la préparation au festival "Les classiques de l'oralité du Tajmyr ». Le texte nganassan a été noté et traduit en russe par Nadežda Kosterkina et subdivisé par elle en plusieurs parties. Dans la première, la partie introductive (lignes 1-12) il est question de la situation, la demande en mariage, qui s'accompagne de commérages et de conversations (qui s'incarnent dans des pierres roulant du haut de la Colline de l'ours et des vents battant un petit arbre isolé au sommet de la colline). La deuxième partie du 
dialogue métaphorique (lignes 13-23) discute de l'objet de la demande en mariage - une jeune fille d'un clan de chamanes, qui est présentée comme le renne que l'on désire, et son origine chamanique est marquée par la présence d'une clochette d'église qui sonne sur le haut de la colline. La troisième partie de la chanson (lignes 24-27) conclut le kejngejrsja par les tournures de circonstance. Les mélodies masculine et féminine du dialogue, qui sont présentées dans les transcriptions musicales 1.1 et $1.2^{8}$, sont dans des registres contrastés, du fait de la différence de timbre des voix. Pour ce qui est de la mélodie, dans les deux elle est fondée sur une cellule dicrote modale oligotonique $\mathrm{a}-\mathrm{h}$, le début de la ligne mélodique étant caractérisé par un un grand bond du volume en cycle de quintes et quartes alternantes. Dans la mélodie de l'homme (exemple 1-1), outre un grand saut dans de la ligne du début, la ligne mélodique descend jusqu'à la quarte inférieure à la fin de certains vers, correspondant à l'intonation descendante de l'exhalation.

Les deux mélodies contrastent au niveau rythmique. La mélodie de l'homme (chant 1-1) est caractérisée par une organisation rythmique en deux temps (les syllabes courtes sont groupées par deux sur des sons longs). Dans la mélodie de la femme (chant 1-2), les durées musicales se groupent en trois (les syllabes courtes sont regroupées par 3 sur des sons longs), qui prévalent au début de la mélodie, et à laquelle s'ajoutent les regroupements rythmiques par deux. Malgré la tendance vers une organisation dipartite et tripartite, il n'émerge pas de ces mélodies de mètre régulier, pas plus que de formules rythmiques stables. Les deux mélodies sont surtout dominées par le principe d'improvisation, qui reflète la spécificité de ce genre : improvisation textuelle libre sous forme de dialogue métaphorique.

Nous trouvons un autre exemple de dialogue d'un jeune homme avec une jeune fille dans un kejngejrsja chanté par S.M. Jarockaja (exemple 2).

L'auteur de ce kejngejrsja est une grand-mère (maternelle) de la famille de S.M. Jarockaja du côté paternel (oncle paternel). La chanteuse l'a entendu chanter par sa mère, TYjmaku Čunanar, demandée en mariage par Modjur Jarockij, une très jolie jeune fille, seule fille entre six frères. La mère de S.M. Jarockaja aimait chanter ce chant, qui lui rappelait la période où elle avait été demandée en mariage et ses noces. S.M. Jarockaja aussi aime chanter cette chanson, elle l'a exécutée dans des festivals de folklore à Dudinka. Le fait qu'un chant dialogique soit chanté en solo (sans partenaire) témoigne de la progressive dégradation de la situation de l'oralité : la communication traditionnelle improvisée devient présentation d'un chant appris par cœur.

Le texte du chant a été écrit en nganassan et traduit par V.Ju. Gusev. Ce dialogue entre un jeune homme et une jeune fille se compose de deux parties. Dans la première (lignes 1-9), le garçon loue la beauté de la jeune fille, comparant son visage rond à la face du soleil et les traits de sa jolie taille aux traits coupés par un couteau ; il exprime le désir de la demander en mariage en payant une large dot. Dans la deuxième partie de la chanson (lignes 10-13) la jeune fille lui répond en rendant tribut à sa belle apparence et en acceptant sa cour.

26 Dans la mesure où il est tout de même question d'un dialogue, deux mélodies apparaissent au cours du chant : celle du garçon et celle de la jeune fille, marquées ici par I (mélodie du garçon) et II (mélodie de la jeune fille).

27 Le chant du garçon (2-1) a une structure mélodique développée : la strophe mélodique se compose de deux ou trois lignes, dont la première commence la strophe avec le son 
le plus élevé rée et évolue dans la direction descendante et ascendante sur un ambitus de quinte $r e^{2}-s i^{1}-s l^{1}$. La mélodie est construite sur des motifs rythmiques de la succession périodique des syllabes longues et courtes (les sons longs caractérisent le début et la fin de la première ligne de chaque strophe). Les lignes suivantes de la strophe peuvent se construire selon l'exemple de la première ligne (mais en commençant sur un son considérablement plus bas $s i^{1}$ ou sol ${ }^{1}$ ), soit sur des intonations contrastées (situées dans un ambitus beaucoup plus bas, une quarte au-dessous du ton principal $\left.r e^{1}-f a^{1}-s o l^{1}\right)$. La mélodie de l'homme comporte seulement de trois strophes complètes et une incomplète (représentée par la première ligne).

La mélodie sans demi-tons du chant de la fille (exemple 2-2) est dominée par des sauts, même si les formules rythmiques et mélodiques n'y émergent pas, comme dans le premier chant. Cependant, par la tonalité, l'ambitus et la structure de succession des sons, le matériau musical du deuxième chant ne contraste pas avec le premier mais se présente plutôt comme un développement et la continuation de ces lignes 2 et 3 . Sauts de quarte descendants et ascendants, avec l'ajout ici et là d'une tierce, caractérisent ce chant (sol $\left.{ }^{1}-r e^{1}-s o l^{1}, s o l^{1}-m i^{1}-r e^{1}, r e^{1}-m i^{1}-s o l^{1}, d o^{2}-s i^{1}-s o l^{1}\right)$.

Les kejngejrsja que je viens d'analyser sont un genre en voie d'extinction, que le dialogue métaphorique chanté soit réel (dans le premier cas) ou mémorisé, devenu œuvre de folklore (dans le deuxième cas).

\section{Les chants personnels}

Passons à l'examen du genre suivant, les chants personnels. Les chants personnels nganassans s'appellent ңонәнә Бәлы (« chant d'un, de moi », « chant d'un, du même ») (Dobžanskaya, Kosterkina 1995, p. 6), ou encore мәнә Бәлы (« mon chant »).

La mélodie du chant personnel est inventée par l'adulte lui-même de son propre chef, à un certain moment dans sa vie, et elle ne changera plus. Ce qui change en revanche, c'est le contenu du chant, son texte. On chante sur tout, sur ce qui inquiète, sur ce qui réjouit ou fait de la peine. On chante en travaillant (par exemple en raccommodant les filets), en chemin, etc. (Dobžanskaya, Kosterkina 1995, p. 6).

Jadis, chaque Nganassan avait son chant personnel, c'est-à-dire sa propre mélodie sur la base de laquelle, décrivant des épisodes de sa vie, il improvisait des paroles. Seul le "propriétaire» (ou l'auteur, pour utiliser un lexique contemporain) d'une chanson avait le droit de la chanter (ou plutôt d'en chanter la mélodie). D’après le témoignage de l'ethnographe G.N. Gračěva,

la mélodie était devenue propriété de la personne, comme ses pensées, sa respiration, ses vêtements... Une personne qui chantait une mélodie autre que la sienne pouvait s'attendre à un châtiment de la part du légitime propriétaire. Ces formes d'«imitation" étaient sérieuses et actives, surtout quand des jeunes Nganassans essayaient de répéter les mélodies de leurs aînés. (Gračëva 1983, p. 56)

En raison de leur caractère d'improvisation, mais aussi à cause des interdits, les chants personnels se sont la plupart du temps perdus. Parfois, les plus réussis, fixés dans la mémoire de proches ou de parents, sont passés parmi les chants folkloriques et pouvaient être exécutés sans autorisation particulière.

33 Je présente ici comme exemple мәнә Бәлы de Syky Modjureevna Jarockaja, que j'ai enregistrée en 2006 à Voločanka. Le texte de la chanson, noté et traduit en russe par V.Ju. Gusev en collaboration avec N.D. Čununčar, décrit la vie de la chanteuse. Elle raconte qu'elle a élevé sept enfants sans compter sur l'aide d'autres personnes. Elle leur 
a confectionné elle-même leurs vêtements "de l'index de la main droite": cette expression reflète la spécificité de la technique utilisée pour coudre les peaux de rennes qui permettent de faire des vêtements d'hiver et qui sont particulièrement rigides. C'est ainsi que pousser l'aiguille avec l'index est un travail lourd, qui provoque des callosités sur le doigt voire des torsions d'articulations. Le chant témoigne de la difficulté de la vie de l'artisane qui passe sa vie à coudre et le fait qu'à la fin de sa vie, elle a pratiquement perdu la vue :

maintenant, je ne vaux plus rien, mes yeux ne voient pas, je ne peux plus coudre (exemple 3)

La mélodie du chant personnel de S.M. Jarockaja (exemple musical 3) repose sur un mode constitué de trois tons sans demi-tons sur un ambitus de quarte : $m i$ - $f a$ dièse - la. Le début du chant par un grand saut descendant $s i$ - mi est typique des débuts de construction mélodique (remarquons que l'étendu de ce saut peut être différente, ce qui fait que ce saut n'a pas de conséquences sur l'analyse de la structure mélodique). Dans ce chant, il ne s'installe pas de formules rythmiques, même si le regroupement caractéristique des durées courtes par trois donne des unités rythmiques instables de trois temps.

Cet exemple représente indiscutablement un cas de figure rare dans le folklore contemporain des Nganassans - dans la mesure où il reste de moins en moins de personnes capables d'improviser et de chanter leur chant personnel.

Un autre exemple de chant personnel est le Chant sur les jeunes filles d'Avam et le garçon de Hatanga, chanté par Ekaterina Subobteevna Kosterkina. Ce chant a été enregistré en 2005 dans le village d'Ust' Avam par V.Ju. Gusev et M.M. Brykina, cette dernière ayant noté le texte nganassan et l'ayant traduit en russe. Le chant raconte l'histoire d'un garçon nommé Kuni, qui va de Hatanga à Ust' Avam pour faire connaissance avec les jeunes filles de cette dernière localité (et éventuellement en demander une en mariage). Le contenu de la chanson nous permet de déduire que c'était le chant personnel de Kuni qui s'est fixé dans les mémoires à Ust' Avam et qui est passé dans le folklore (exemple 4).

37 La mélodie (exemple musical 4) est une mélodie typique des chants personnels nganassans. Le début de chaque ligne est marqué par un saut de quinte descendante la ré, qui forme une forme initiale à deux sons. La partie centrale de la ligne mélodique est construite sur une oligotonique de trois sons sans demi-tons (ou, autres possibilités, sur le tricorde $l a-s i-r e^{1}$ ou le triton $l a-s i-d o$ dièse $\left.\mathrm{e}^{1}\right)$. À la fin de chaque ligne émerge une formule mélodique et rythmique $(s i-l a)$ sur des mots de remplissage. D'une façon générale, on peut remarquer la tendance de la structure rythmique vers une organisation en deux temps, qui ne s'installe que dans la deuxième moitié du chant.

\section{Chant de boisson}

Un autre type différent de chants est représenté par les ХоАңкутуо Бәлы (chanson de table, chant de boisson, mot-à-mot "chant d'une personne ivre »). Il s'agit là d'une manière psychédélique de chanter sous l'influence de l'alcool. Les хоАңкутуо Бәлы sont apparus plus tardivement que les chants personnels et progressivement,

avec le rejet dans le passé de nombreux traits de la vie traditionnelle nganassane, ces chants ont peu à peu supplanté les chants personnels, tout en assumant leur mise en forme mélodique (Dobžanskaya, Kosterkina 1995, p. 7) 


\section{de la personne :}

en général, la personne parle des choses les plus secrètes, dissimulées, des offenses subies, des échecs <...> elle demande aux dieux (aux esprits) du succès, exprime son espoir de réussite <...> il y a aussi des chansons grivoises (Dobžanskaya, Kosterkina 1995, p. 7-8)

En raison de la difficulté que l'on rencontre à différencier les genres du chant personnel et du chant de boisson, nous ne présenterons pas ici d'exemples de ces derniers.

\section{Les chants d'enfants}

Les chants d'enfants, njuo bəly, représentent une autre des ramifications de la tradition du chant nganassan.

Les chants d'enfants ne sont pas des berceuses, mais ils ne sont pas non plus le résultat de créations par des enfants. Les mélodies de ces chants, de même que leurs paroles, sont conçues par les parents à l'intention de leurs enfants. <...> De toute évidence, ces chants se présentent comme des mélodies-formules, qui sont nées à l'origine d'observations sur les manières de faire, sur les manifestations du caractère de l'enfant, sur sa manière de marcher, sur ses premiers mots ou les premiers sons qu'il prononce. Ensuite, elles peuvent être complétées par n'importe quel contenu. (Dobžanskaya, Kosterkina 1995, p. 8)

D'après N.T. Kosterkina, jadis ces chants avaient une fonction magique de protection, mais servaient aussi de jouets, de passe-temps pour les enfants, de modèles pour leur éducation musicale (ibid.).

Je voudrais présenter, en guise d'exemple de нюо вәлы, le chant d'enfant de Derkuptie, qui a été enregistré en 1990 à Voločanka et qui est chanté par Valentina Bintaleevna Kosterkina (exemple 5). Le texte de la chanson, noté et traduit par N.T. Kosterkina, se présente comme du discours direct de l'enfant, passant par les lèvres de sa mère. Le petit Derkuptie, qui est couché dans son berceau, s'adresse aux présents :

Pourquoi autour de moi vous êtes-vous rassemblés, entassés? Simplement je vis ainsi (je me réjouis), c'est pourquoi vous ne me dérangez pas.

Le caractère enjoué de ce chant est représentatif du genre en général. Il se manifeste dans la manière dont il est chanté (avec le sourire, en riant), par le choix des moyens lexicaux (la chanteuse imite les adorables imperfections de parole de l'enfant, introduit des sons particuliers et des mots enfantins, tels qu'ils sont prononcés par l'enfant quand il apprend à parler), par le sujet de la pièce, décrivant l'enfant occupé à des activités enfantines, à des jeux, etc.

La mélodie du chant de Derkuptie (exemple 5), comme on peut le remarquer, est influencée par les berceuses, avec leur rythme stable et leurs répétitions. On le constate dans l'organisation rythmique en deux parties et dans les formules rythmiques, pour lesquelles la chanteuse introduit délibérément dans le vers des syllables de remplissage (dépourvues de sens) ว-wə-ə-wə, ə-hə-ə-hə, hy-y-hy etc. Ces syllabes de remplissage s'identifient facilement dans la notation musicale (elles sont notées entre parenthèses). 


\section{Les berceuses} aussi bien par le père, par la mère ou par d'autres membres de sa famille de l'enfant. Les berceuses nganassanes sont appelées njuo ljandyrsibsja («bercer l'enfant »), et ne sont pas vraiment des chants dans la mesure où elles n'ont pas de texte ou de sujet développé. Il s'agit plutôt d'intonation mélodique de certains mots ou de certaines syllabes. Parmi les traits typiques, l'allongement rythmique sur les syllabes kehej-kehej, kehej-kA - kehej-kA, kuntudi- kuntudi, oljou- oljou et la combinaison de ces syllabes, qui accompagnent le mouvement de l'enfant bercé sur les genoux de ses parents. En mesure avec ce balancement, on entend sonner doucement les hochets et pendentifs en métal et en os suspendus au cintre du berceau. Parfois, le chanteur fait passer en avant et en arrière sur le cintre dentelé du berceau une baguette qui produit un certain grincement.

En plus de l'intonation chantante destinée à endormir l'enfant, les Nganassans utilisent aussi des formes non chantées de comportement sonore. Pour le décrire : la langue se déplace rapidement en direction horizontale entre les lèvres arrondies, dans la position que prend l'appareil buccal pour articuler le son « $\mathrm{O}$ ». Ce type de production sonore, qui peut être défini comme labio-lingual, s'utilise à côté des berceuses traditionnelles ou à leur place. Nous avons enregistré un exemple de ce type de production sonore produit par Valentina Bintaleevna Kosterkina en 1990 au village de Voločanka, qui figure à l'exemple musical 6 .

\section{Conclusion : les problèmes du maintien de la tradition du chant nganassane et la situation actuelle}

La publication d'échantillons éloquents de textes et de mélodies uniques, irremplaçables, ne garantit en rien la préservation des chants dans la culture nganassane. Pour les Nganassans d'aujourd'hui qui essayent de chanter un chant traditionnel, il apparaît souvent problématique de reproduire le timbre caractéristique des chants nganassans. L'intonation spécifique, propre à la manière nganassane de chanter, tient à l'alternance des timbres nasalisés et pharyngalisés, à l'utilisation du vibrato, de la pulsation rythmique, du glissando et d'autres moyens qui ne peuvent être notés sur les partitions (prévues avant tout pour les mélodies de type européen) que de manière extrêmement approximative. Ceci montre que pour reproduire de manière adéquate les chants nganassans, un chanteur d'aujourd'hui doit non seulement apprendre des textes et des mélodies, mais aussi se concentrer sur l'acquisition des timbres nécessaires. Il doit écouter beaucoup d'enregistrements pour essayer de reproduire à l'identique la manière dont sonnent les voix des chanteurs traditionnels. En effet, le phénomène du chant nganassan ne peut pas être préservé sans la conservation précise du timbre.

De manière générale, le problème de la préservation du chant traditionnel et, plus largement, de la culture musicale des Nganassans, est complexe. Elle implique d'abord qu'on prenne des mesures pour garantir l'existence de sources et d'une base méthodologique pour étudier la chanson (publication de recueils et de littérature spécialisée) ; deuxièmement, qu'on organise des groupes spéciaux consacrés au chant 
nganassan dans les maisons de la culture ou dans les établissements d'enseignement. De plus, la question de créer un milieu multiculturel bienveillant se pose avec insistance si l'on veut développer ce genre de pratique créative. Il faut l'aborder par l'organisation d'initiatives, de concerts, de master-classes et d'autres formes d'actions destinées à populariser l'art musical de ce petit peuple du Nord dans la culture multiethnique de la Russie.

Dans la culture nganassane actuelle, le chant se conserve surtout grâce à l'action des institutions culturelles (maisons rurales de la culture à Voločanka, à Ust' Avam, Centre urbain de la création populaire et maison de la création populaire du Tajmyr, à Dudinka). Le cercle de chant nganassan "Hendir» (sous la direction de S.M. Kudrjakova) et le groupe "Dentadie» (sous la direction de S.N. Žornickaja) popularisent la culture musicale nganassane, même si les formes innovantes - chant accompagné de phonogrammes, mises en scène spéciales - dominent. L'art traditionnel du chant se maintient uniquement dans le répertoire des Nganassans de la génération la plus âgée qui sont encore en vie.

\section{BIBLIOGRAPHIE}

GRAČEVA Galina 1983 = ГРАЧЕВА ГАЛИНА НИКОЛАЕВНА, ТРАДИЦИОННОЕ МИРОВОЗЗРЕНИЕ ОХОТНИКОВ ТАЙМЫРА (НА МАТЕРИАЛАХ НГАНАСАН ХІХ-ХХ ВЕКА) (La vision du monde traditionnelle des chasseurs du Tajmyr sur la base de matériaux nganassanes des $\mathrm{XVI}^{\mathrm{e}}$-XX $\mathrm{X}^{\mathrm{e}}$ siècles), лЕНИНГРАД: НАУКА, ЛЕНИНГР. ОТДЕЛЕНИЕ.

DOBŽANSKAJA Oksana 2008 = ДОБЖАНСКАЯ ОКСАНА ЭДУАРДОВНА, ШАМАНСКАЯ МУЗЫКА САМОДИЙСКИХ НАРОДОВ КРАСНОЯРСКОГО КРАЯ (La musique chamanique des peuples samoyèdes du kraï de Krasnojarsk), ноРИЛЬСК : изд-во АПЕКс.

DOBŽANSKAJA Oksana 2014 = ДОБЖАНСКАЯ ОКСАНА ЭДУАРДОВНА, «ПЕВЦЫ И ПЕСНИ АВАМСКОЙ ТУНДРЫ» (Chansons et chanteurs de la toundra d'Avam, in dir. О.Э. ДОБЖАНСКАЯ, ЗАПИСЬ ТЕКСТОВ НА НГАНАСАНСКОМ ЯЗЫКЕ И ПЕРЕВОД НГАНАСАНСКИХ ТЕКСТОВ - Н.Т. КОСТЕРКИНА, К.И. ЛАБАНАУСКАС, В.Ю. ГУСЕВ, М.М. БРЫКИНА (Notation de textes en nganassane et traduction de textes nganassanes de N.T. Kosterkina, K.I. Labanauskas, V.Ju. Gusev, M.M. Brykina), НоРИЛьск: АПЕКС. DOBŽANSKAJA Oksana, KOSTERKINA Nadežda 1995 = ДОБЖАНСКАЯ ОКСАНА ЭДУАРДОВНА, КОСТРЕКИНА НАДЕЖДА.ТУБЯКОВА, ПЕСНИ НГАНАСАН (Les chants des Nganassanes), СОСТ. И МУЗ. РЕДАКТОР О.Э. ДОБЖАНСКАЯ, КРАСНОЯРСК: КНИЖНОЕ ИЗДАТЕЛЬСТВО.

DOLGIH Boris, FAJNBERG Lev 1960 = ДОЛГИХ БОРИС ОСПИВИЧ, ФАЙНБЕРГ ЛЕВ АБРАМОВИЧ, «ТАЙМЫРСКИЕ НГАНАСАНЫ» (Les Nganassanes du Tajmyr), in dir. БОРИС ОСИПОВИЧ ДОЛГИХ СОВРЕМЕННОЕ ХОЗЯЙСТВО, КУЛЬТУРА И БЫТ МАЛЫХ НАРОДОВ СЕВЕРА (L'économie, la culture et la vie quotidienne des petits peuples du Nord), МОскВА, 9-62.

HELIMSKIJ Evgenij 1989 = ХЕЛИМСКИЙ, ЕВГЕНИЙ АРНОЛЬДОВИЧ, «СИЛЛАБИКА СТИХА В НГАНАСАНСКИХ ИНОСКАЗАТЕЛЬНЫХ ПЕСНЯХ » (Le vers syllabique dans les chants métaphoriques 
nganassanes), in dir. Ю. И. ШЕЙКИН, МУЗЫКАЛЬНАЯ ЭТНОГРАФИЯ СЕВЕРНОЙ АЗИИ (Еthnographie musicale de l'Asie du Nord), НовосИБИРск, 52-76.

НОМІС̌ Ljudmila 1995 = ХОМИЧ ЛЮДМИЛА ВАСИЛЬЕВНА, НЕНЦЫ: ОЧЕРКИ ТРАДИЦИОННОЙ КУЛЬТУРЫ (Les Nénetses : essais sur une culture traditionnelle), САНКТ ПЕТЕРБУРГ: РУССКИЙ ДВоР.

KUPRIJANOVA Zinaida 1960 = КУПРИЯНОВА, ЗИНАИДА НИКОЛАЕВНА, НЕНЕЦКИЙ ФОЛЬКЛОР: УЧЕБ. ПОСОБИЕ ДЛЯ ПЕД. УЧИЛИЩ (Le folklore nénetse), сост. 3.Н. КУПРИЯНОВА, ЛЕНИНГРАД: УчПЕдГиз.

LABANAUSKAS Kazimir 1992 = ЛАБАНАУСКАС, КАЗИМИР ИЗИДОРОВИЧ., ФОЛЬКЛОР НАРОДОВ ТАЙМЫРА. НГАНАСАНСКИЙ ФОЛЬКЛОР (Le folklore des peuples du Tajmyr. Le folklore nganassane), ДУДИНКА. NIEMI Jarkko $2004=$ Network of songs (Individual songs of the Ob' Gulf Nenets: Music and local history as sung by Maria Maksimovna Lapsuj), Helsinki: Société Finno-Ougrienne.

SIMČENKO Jurij 1963 = СИМЧЕНКО ЮРИЙ БОРИСОВИЧ, «ПРАЗДНИК АНЫ"О-ДЯЛЫ У АВАМСКИХ НГАНАСАН» (La fête Any' odjaly chez les Nganassanes de l'Avam), тРУдЫ ИНСТИТУТА ЭТНОГРАФИИ (Travaux de l'institut d'ethnographie), НовАЯ СЕРИЯ, т. 84, МОскВА, 168-179. (СИБИРСКИЙ эТНОГРАФИЧЕСКИЙ СБОРНИК. ВЫП.V).

SIMČЕNКО Jurij 1976 = СИМЧЕНКО ЮРИЙ БОРИСОВИЧ, КУЛЬТУРА ОХОТНИКОВ НА ОЛЕНЕЙ СЕВЕРНОЙ ЕВРАЗИИ. ЭТНОГРАФИЧЕСКАЯ РЕКОНСТРУКЦИЯ (La culture des chasseurs de rennes de l'Eurasie septentrionale. Une reconstruction ethnographique), МОСКВА: НАУКА.

\section{ANNEXES}

\section{Annexe 1 - Les chanteurs nganassanes}


Les chansons des Nganassans

12

Valentina Bintaleevna Kosterkina (1938-1998)

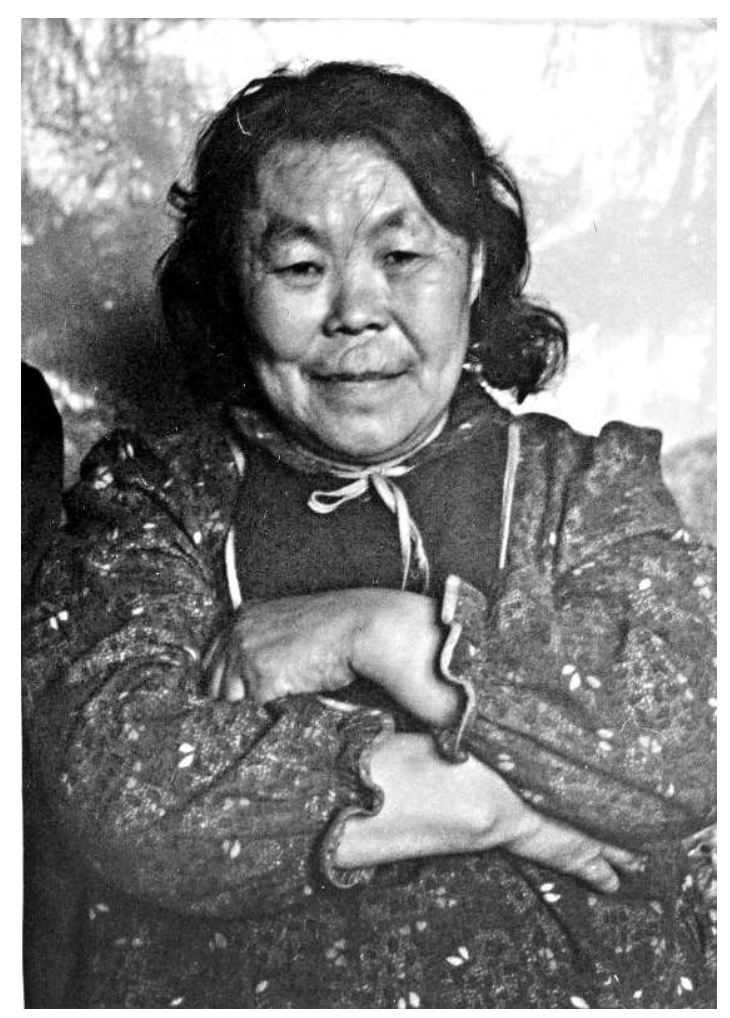

Village de Voločanka, photo de Oksana Dobžanskaja.

Den'čude Nuteevič Mirnyh (1923-2006)

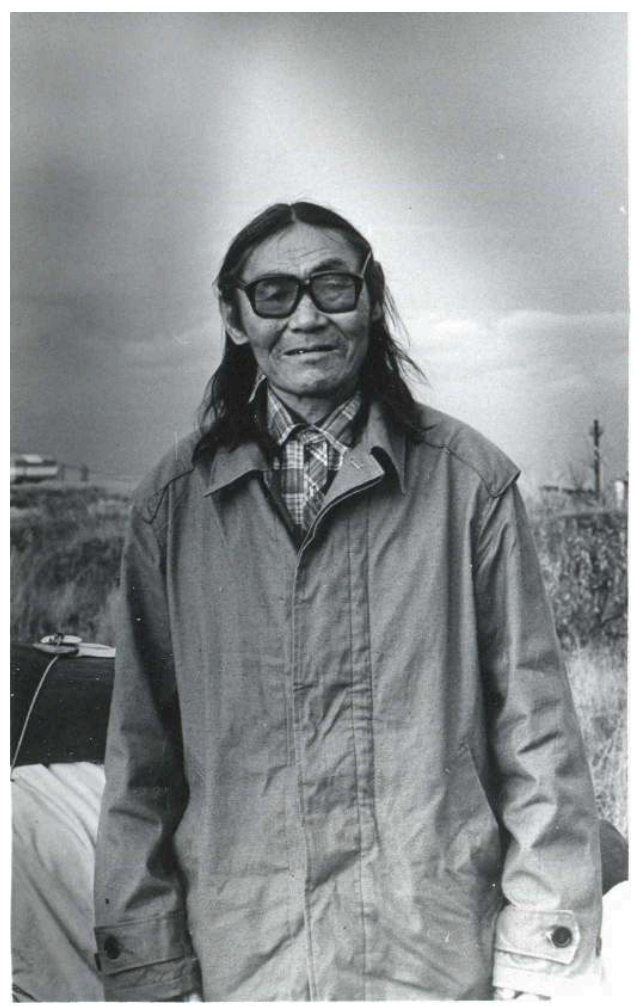

Village de Voločanka, photo de Oksana Dobžanskaja.

Études finno-ougriennes, 47 | 2015 


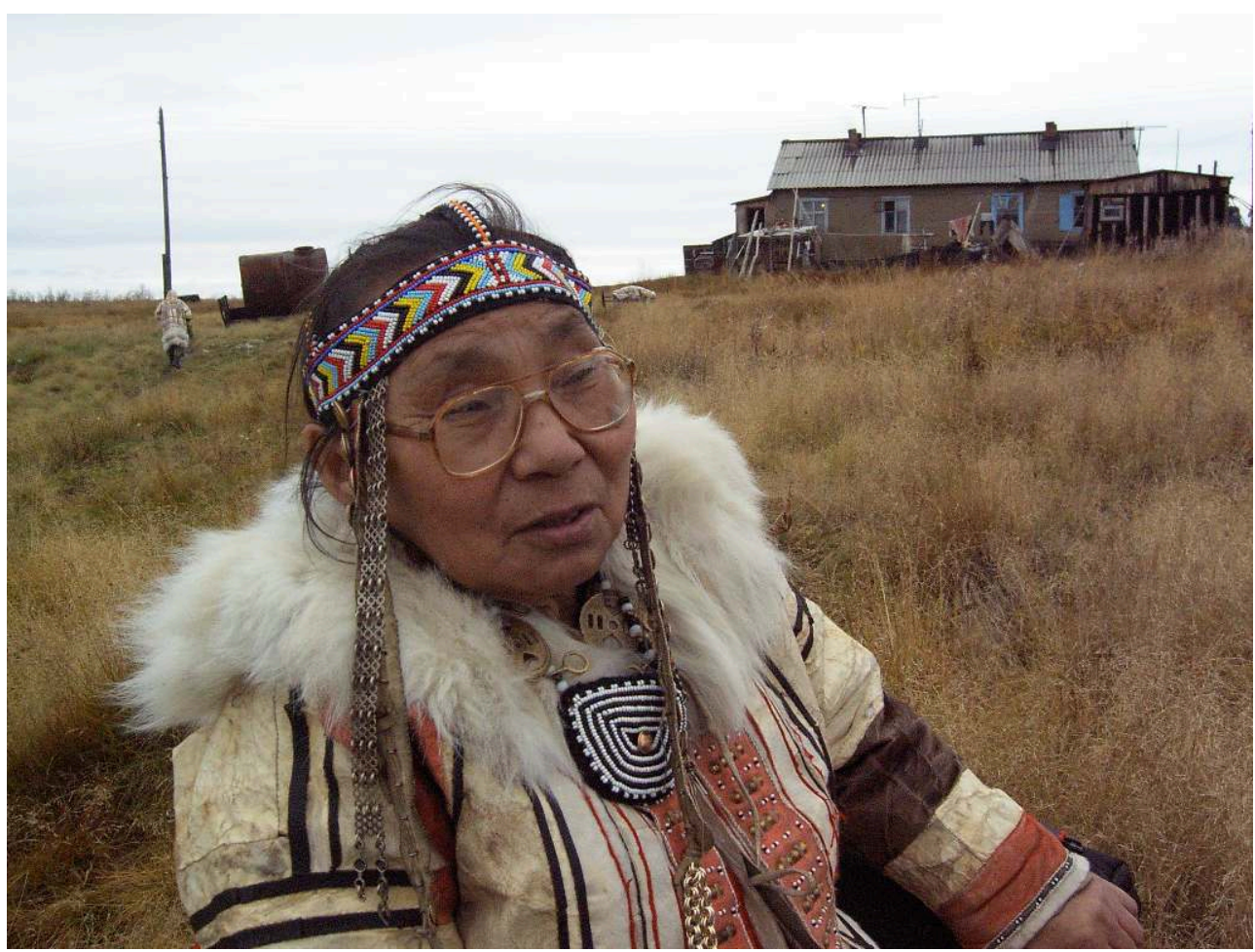

Village de Voločanka, photo de Oksana Dobžanskaja

Ekaterina Subobteeva Kosterkina (1940-2009)

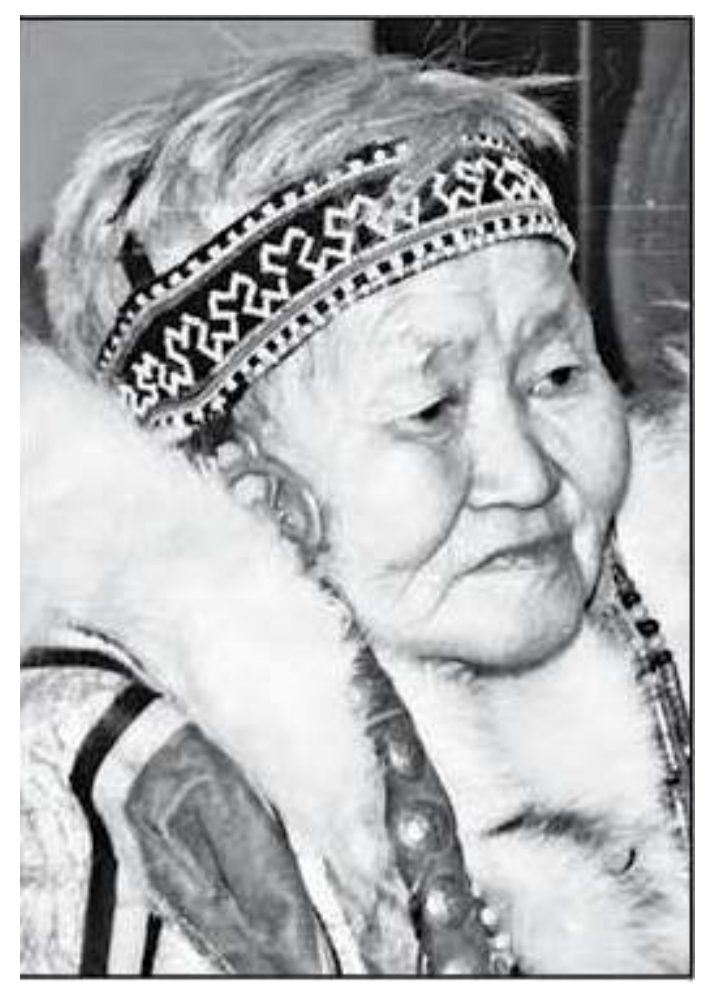

Village d'Ust' Avam, photo de D. Koževnikov. 


\section{Annexe 2 - Les textes des chansons et les partitions \\ Exemple 1}

\section{Kejngejrsja}

Dialogue métaphorique chanté

Valentina Bintaleevna Kosterkina et Den'čude Neteevič Mirnyx

Enregistrement : 1996, Dudinka, o.E. Dobžanskaja.

Texte en nganassan et traduction : N.T. Kosterkina.

\begin{tabular}{|c|c|c|}
\hline \multicolumn{3}{|c|}{ D.N.Mirnyx } \\
\hline 1 & мәнә мУнУгузૅวМм & Je dis : \\
\hline 2 & НИМЛЯНКӘ НАРКА ДИКӘРА”А & de la célèbre (grande) Colline de l'ours \\
\hline 3 & кунУ ниНы мУнә, & quelqu'un l'a dit, \\
\hline 4 & САЁૅУЙ ТИИРАИ" ХОАЛӘЙ & de la taille d'un nuage, argileuses \\
\hline 5 & нюонтәсА нянсу"тули"индә". & des pierres ont roulé. \\
\hline 6 & НАРКА ДИГә & \\
\hline \multicolumn{3}{|c|}{ V.B.Kosterkina } \\
\hline 7 & тунымыз̆ә ни & Sur la colline de l'Ours \\
\hline 8 & НИРКУ”АКУ ХУА & sur son sommet \\
\hline 9 & ХУА БИНЕ"ПТУНДЫ" & un aulne petit arbre \\
\hline 10 & ХОАРА"ЛУСА БИЭТЭ ХОАРА"ЛУСА & un petit arbre ploie, \\
\hline 11 & БинЕ”птунды", & plié par le vent, le vent \\
\hline 12 & ХУА БИНЕ"ПТУНДЫ". & battu, \\
\hline \multicolumn{3}{|c|}{ D.N.Mirnyx } \\
\hline 13 & тәгәтә мУнУгУм & Après quoi moi je dis : \\
\hline 14 & НЮО САНИ ТАА & un jouet, un renne, \\
\hline 15 & кәБәәмә ТАА ${ }^{1}$ & un renne, ma part \\
\hline 16 & НАМТә БИНҮ"КҮчУ². & a replié ses bois. \\
\hline \multicolumn{3}{|c|}{ V.B.Kosterkina } \\
\hline 17 & НАРКА ДИКӘРӘ & Sur la colline de l'Ours, \\
\hline 18 & тунымыз̆ә ни & sur son sommet \\
\hline 19 & 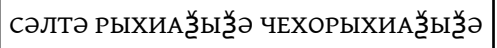 & dans le poteau, il appert, ont été enfoncés \\
\hline 20 & ЧЕБӘНТӘНЫ ЧЕТӘ ЧЕБӘНТӘНЫ & quatre clous. \\
\hline 21 & ТӘНДә ЧЕБӘНТәНЫ & sur ces clous \\
\hline 22 & 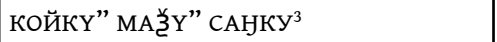 & une clochette d'église, \\
\hline
\end{tabular}




\begin{tabular}{|c|c|c|}
\hline 23 & САНКУ КИ"РИРИ. & Une clochette tinte. \\
\hline \multicolumn{3}{|c|}{ D.N.Mirnyx } \\
\hline 24 & БӘЛТАМӘ ДЮЛСЫМӘ & C'est tout pour moi, j'ai terminé, \\
\hline 25 & мәнә мысиэгуәнә. & Moi (j'ai fini ma chanson). \\
\hline \multicolumn{3}{|c|}{ V.B.Kosterkina } \\
\hline 26 & МЫ"чЕНӘ ТӘПТӘ & et moi aussi, \\
\hline 27 & сяз゙̌ы"ини", тәсиә сяз्己ы"ини" & nous avons terminé. \\
\hline
\end{tabular}

Mélodie 1, chantée par D.N.Mirnyh
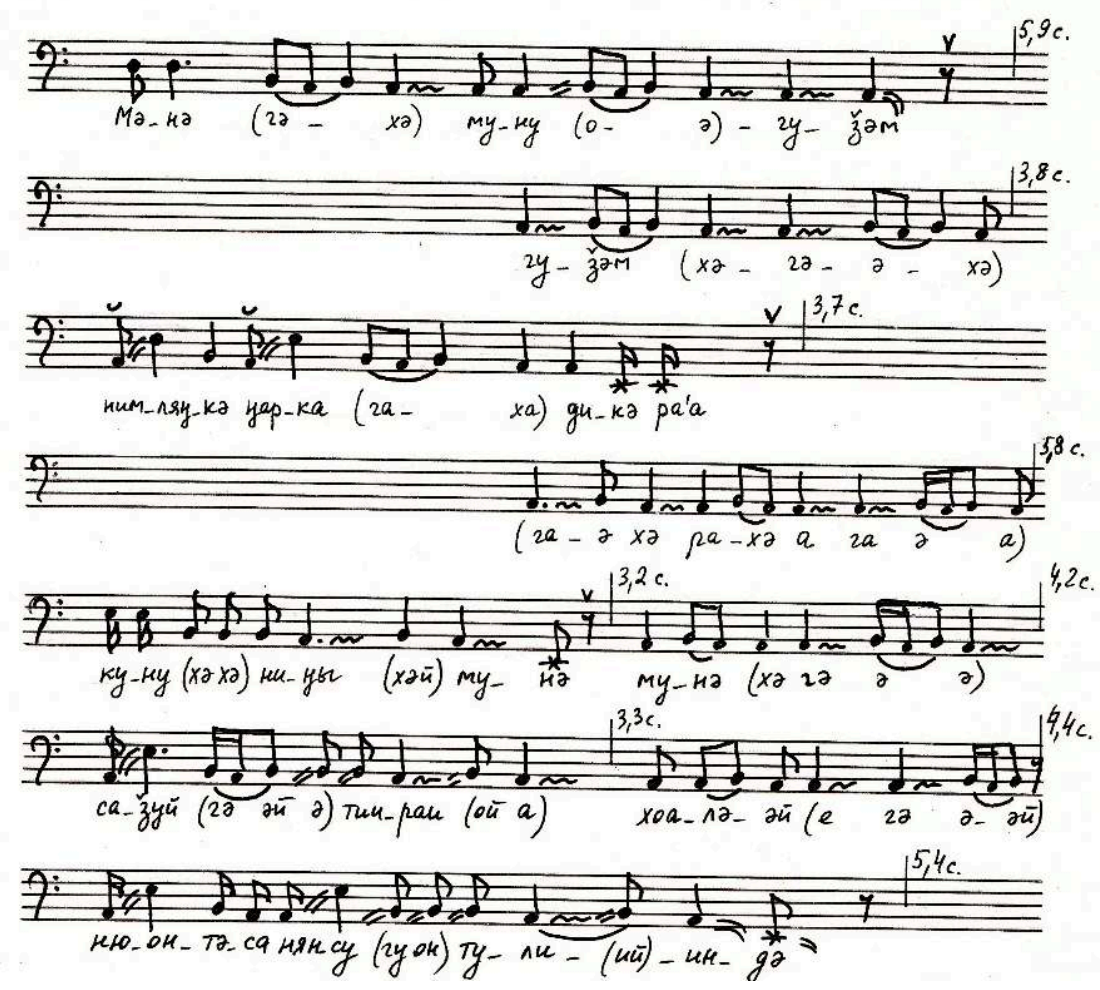
Mélodie 2 chantée par Valentina Kosterkina

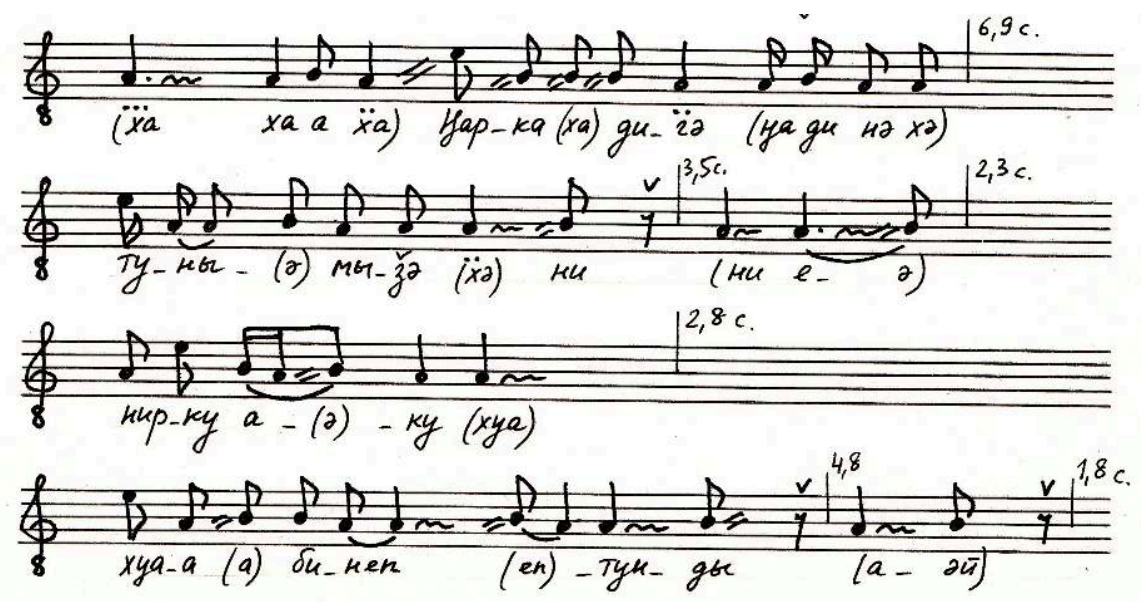

Mélodie 2 chantée par Valentina Kosterkina (suite)
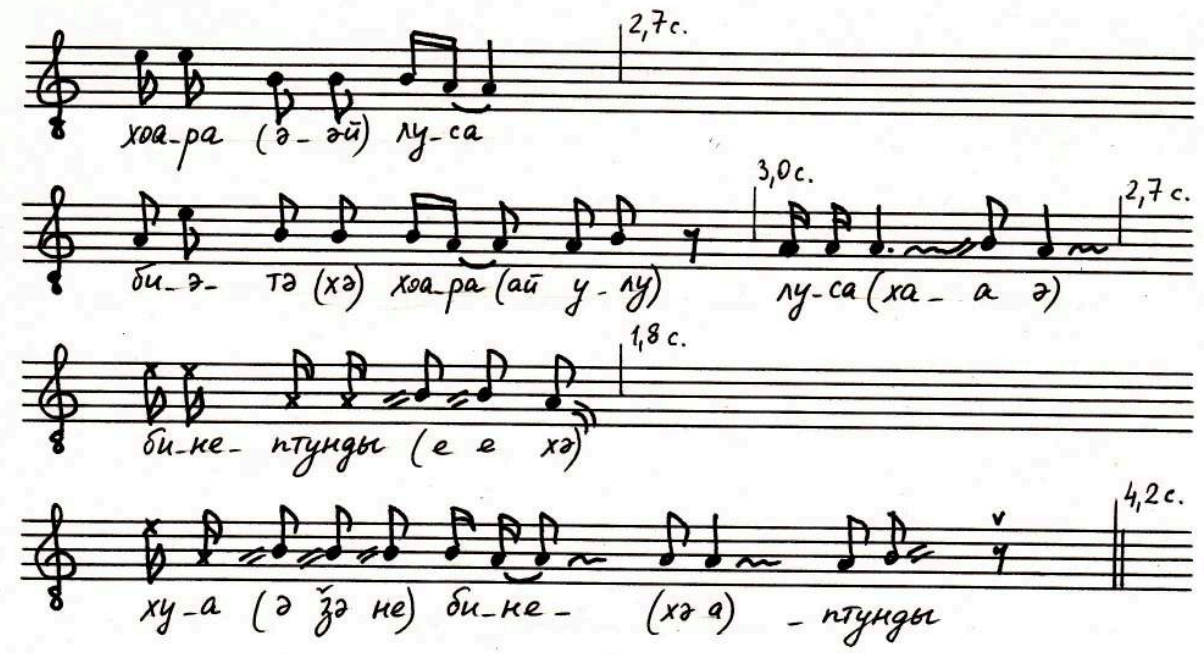

\section{Exemple 2}

\section{Kejngejrsja}

Chant métaphorique

Syku Modjureevna Jarockaja

Enregistrement : 2006, village de Voločanka, O.E. Dobžanskaja

Notation du texte : В.Ю. ГУСЕВ,

Texte traduit et vérifié à l'aide de N.D. Čunančar et d'E.S. Kosterkina

\begin{tabular}{|c|c|c|}
\hline 1 & мәнә тәнә әрәкәрәмәны мәнюнтүм & Ton visage rond comme celui du soleil. \\
\hline 2 & ХОРӘГӘЧЕЛЬЧЕРӘ КОУ ХОРӘРӘКУ ДЮЙХУАКА"КУ. & $\begin{array}{l}\text { Pour t'épouser je payerai une grande } \\
\text { dot }\end{array}$ \\
\hline
\end{tabular}




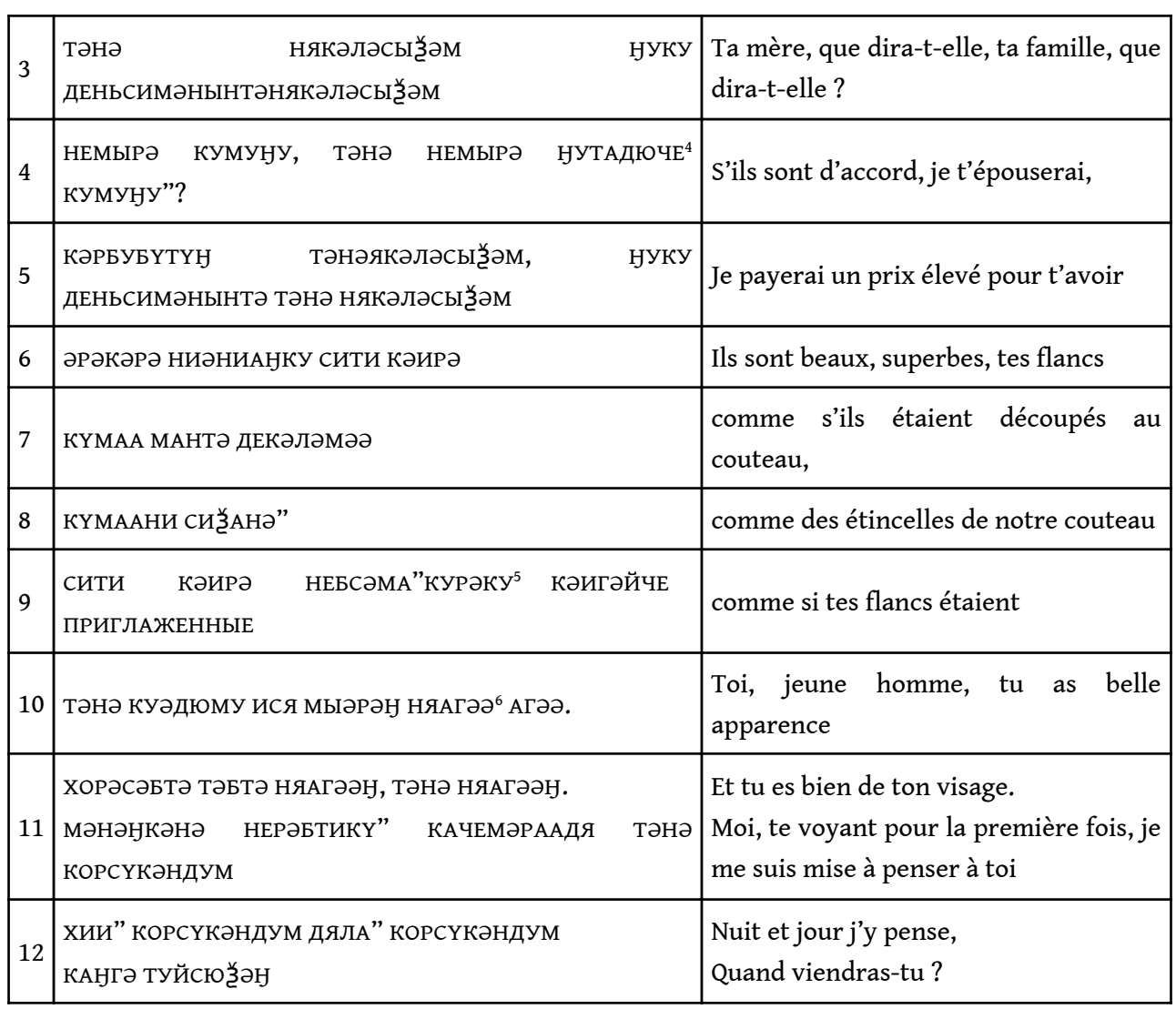

\section{Commentaire}

Le chant se compose de deux parties : d'abord, c'est le jeune homme qui chante, déclarant son amour à la jeune fille (lignes 1-9), puis la jeune fille lui répond (lignes 10-13).

C'est pourquoi on trouve dans ce chant deux mélodies, celle du garçon et celle la jeune fille, qui sont chantées d'après les lignes correspondantes de la chanson (d'abord au nom du garçon, puis de la jeune fille).

Ce chant peut être chanté sur scène, mettant en scène le dialogue entre les deux jeunes.

Mélodie du jeune homme

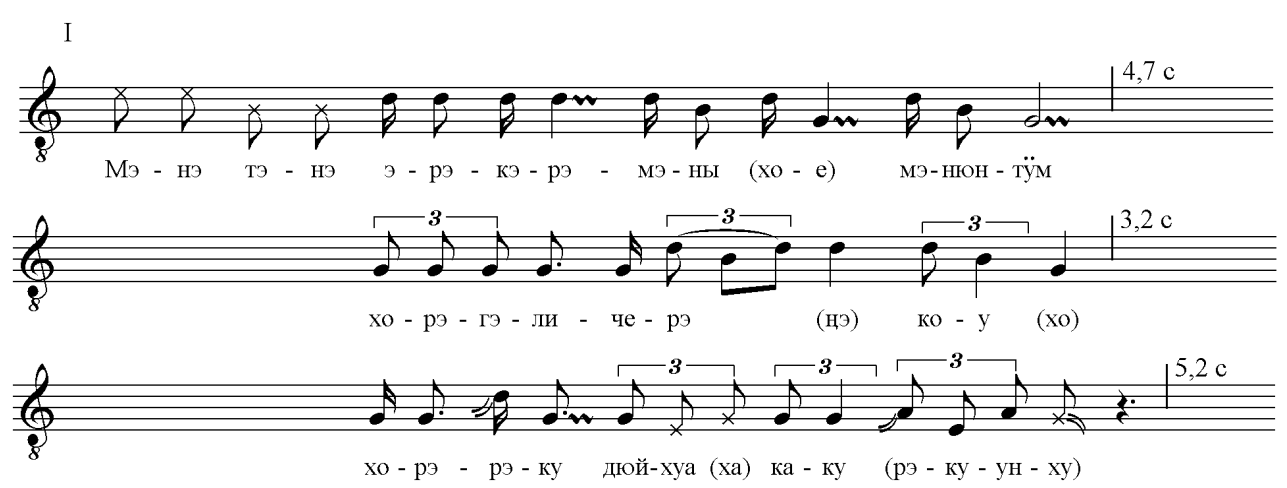


II

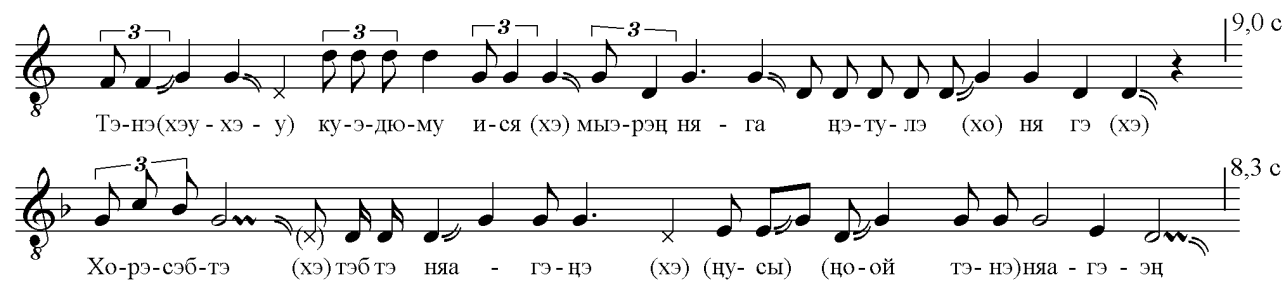

\section{Exemple 3}

\section{МәНә БАЛЫ - chant personnel}

Syku Modjureevna Jarockaja

Enregistrement : Voločanka 2006, O.E. Dobžanskaja

Notation et traduction du texte : V.Ju. Gusev,

Texte traduit avec l'assistance de N.D. Čunančar et de E.S. Kosterkina.

\begin{tabular}{|c|c|}
\hline МӘНӘ ХУАНКУБСАМӘ БӘЛЫМӘ ДЕБТУ"КИ"ӘМ & Je chante mon chant personnel \\
\hline СЯЙБАНКУ ЛАБСӘМӘ МӘНӘ БӘТУДЮӘМ, & Mes sept enfants j'ai élevés \\
\hline әмә дюટ̌Үтининә вәтудюәм & De mes mains je les ai élevés. \\
\hline МәНә сЯЙБӘМә ЛАБСәМә БәТУДюวМ & J'ai élevé sept enfants \\
\hline НУ”әи" КОДюКАЛИ БәТУДюә & Sans la moindre décoration. \\
\hline БәТУДюӘМ ДЕМБИЛИСИИНЕ & Je les ai élevés, habillés \\
\hline НАНА"САНУ" ДЯ ДЕНХИАЗૅИЧУН & Je n'ai pas acheté leurs vêtements \\
\hline НИГәТЫМ ТАМТУә". & Aux gens, je les ai faits moi-même. \\
\hline ӘМӘ ТЫМИНИАҢ МӘНӘ НАНА"САНӘЙ & Maintenant, sans doute, les gens \\
\hline нәндиАи" нигәтым ху". & Je n'en veux pas. \\
\hline Мәнә нюә нюәй БәтУдюәм & Moi, des enfants, moi, je les ai élevés \\
\hline әмә нюәмә Бәтудюәм, & J'ai élevé des enfants, \\
\hline хуәмә БәтУдюәм & toutes ces années \\
\hline НюəНЕ, НюəЙ БӘТУДюəМ, & Des enfants, j’ai élevés, moi je les ai \\
\hline МәнӘ БӘТУДЮәМ, МАМәУ. & Elevés à la maison. \\
\hline МӘНӘ НАНА"САНУ" ДЯ НИСЫӘМ ДЕНӘЁЫЧИ, & Je n'ai pas flatté les gens \\
\hline нИСЫәм ДЕНӘこ̌ЫЧИ, НИСЫәм чУСҮРҮБТҮКү" & Je n'ai pas demandé de l'aide, \\
\hline МӘНӘ МАНТИМҮ НҮХӘУМӘ, & De l'index de la main droite \\
\hline СОЧЕЛӘСУӘМ & j'ai cousu. \\
\hline НЮӘЙ ДЕМБИЛИСИИНЕ МӘНӘ & Mes enfants, je les ai \\
\hline ДЕМБИЛИСИИНЕ & habillés. \\
\hline
\end{tabular}




\begin{tabular}{|c|c|}
\hline ӘМИА"КУ НҮХӘУНӘ МЕЙСИӘМ & Cousu de mon index \\
\hline ДЕНХИАЗ̌ЫЧИН НУСЫ"КәНДЫМ, & un habit je leur couds, \\
\hline мәнә нУсы"кәндым. & un habit je couds. \\
\hline ТЫМИНИАКҮӘ НӘНХУәМ, & Maintenant je ne vaux plus rien \\
\hline МӘНӘ ТЫМИНИА МАА, СЕЙМЫНЕ ДЯНГУ”. & Mes yeux ne voient pas, je ne peux plus coudre. \\
\hline
\end{tabular}
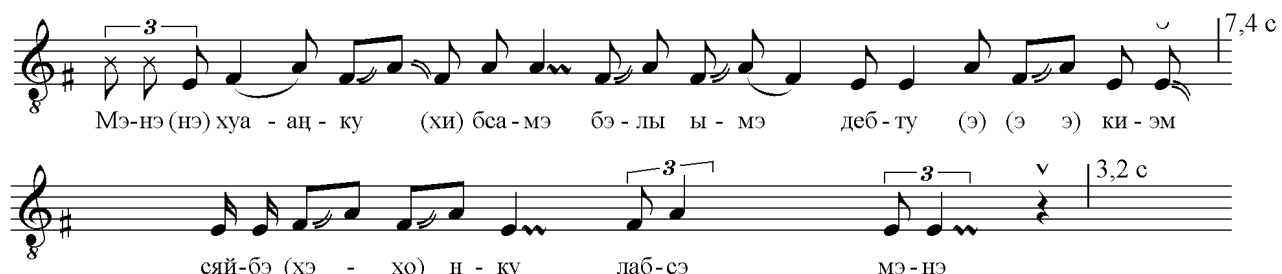

еяй-бэ (хэ - хо) Н - ку лаб-сэ МЭ-нэ
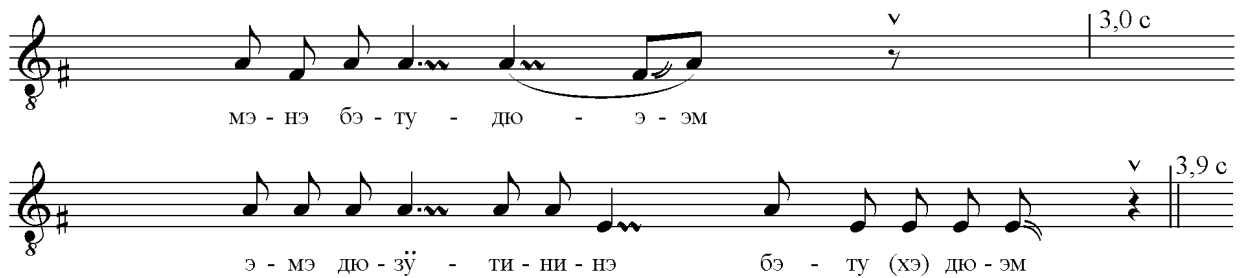

\section{Exemple 4}

\section{Njuo Baly}

Chant d'enfant de Derkuptie

Valentina Bintaleevna Kosterkina,

enregistré à Voločanka en 1990 par o.E. Dobžanskaja et V.S. Nikiforova

Texte en nganassane et traduction en russe par N.T. Kosterkina

\begin{tabular}{|c|c|}
\hline КУНДӘ НАНӘ & Pourquoi autour de $\mathrm{moi}^{7}$ \\
\hline ЛюМКҮНАНДУ” ? & vous vous êtes rassemblés, entassés? \\
\hline кәРУТӘНә НИЛЫТИАКУ & Je me contente de vivre. \\
\hline ТААНИЭМТУ" & Vous veillez \\
\hline НəЕ̌YHYРY". & sur les vôtres. \\
\hline КӘМСәМУОЛИ" СЕТӘГӘ & Il est chef du komsomol ${ }^{8}$. \\
\hline мәймәдЕодю кәлсуйчиты ${ }^{9}$ & Son menton est proéminant (tant il est important) \\
\hline ДЕРКУПТИЭ ДЕДЯТЫТЫ & Derkuptie sourit, \\
\hline ДЕРКУПТИЭ ДЕБЯТЫТЫ & Derkuptie a les joues colorées. \\
\hline кәрУТәНә НИЛЫТИАКУМ & Simplement je vis ainsi (je me réjouis), \\
\hline МәнӘ нИНЫРЫ" ляМУПТИАЛЫ". & C'est pourquoi vous ne me dérangez pas. \\
\hline
\end{tabular}



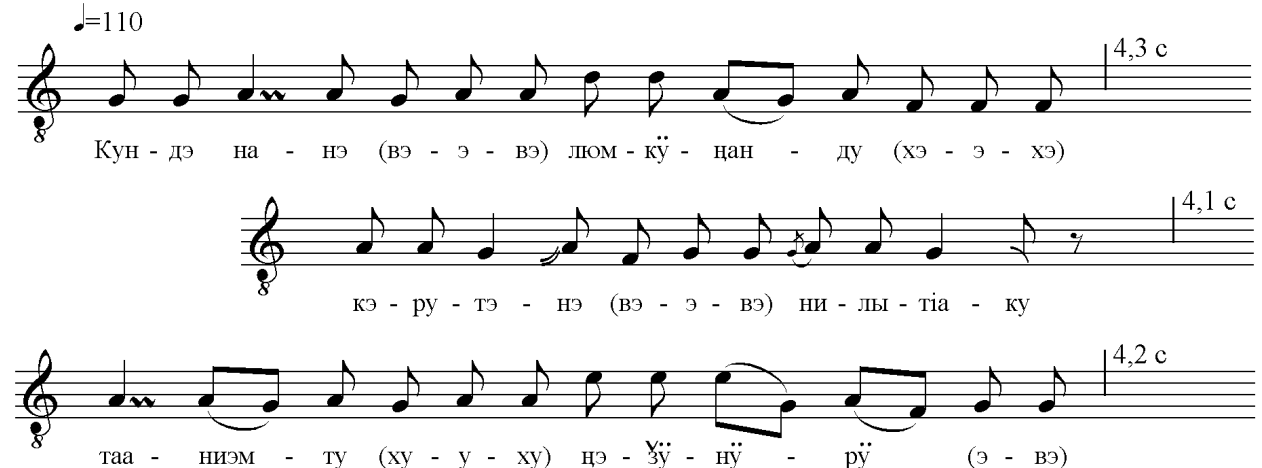

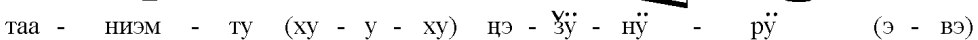
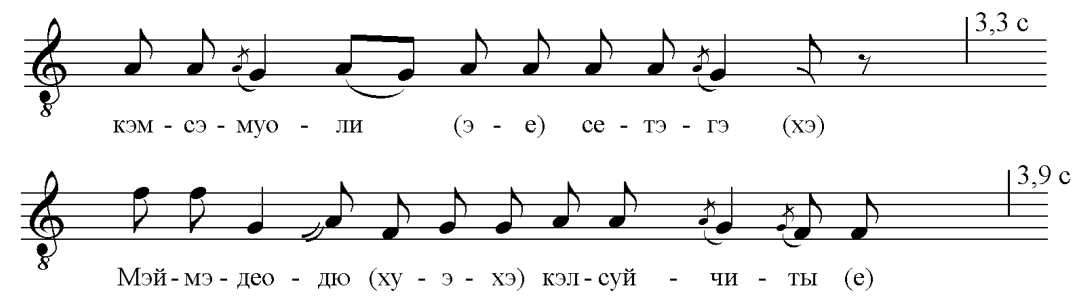

\section{Exemple 5}

\section{Baly}

Chant sur les jeunes filles d'Avam et sur le garçon de Hatanga

Ekaterina Subobteevna Kosterkina

Enregistré à Ust'-Avam en 2005 par V.Ju. Gusev et M.M. Brykina

Texte en nganassan et traduction en russe M.M. Brykina

\begin{tabular}{|c|c|}
\hline КУНИ ТУЧАТЫТЫ АВАМА"А ДЯ & Kuni ${ }^{10}$ va tout droit à Ust'-Avam. \\
\hline 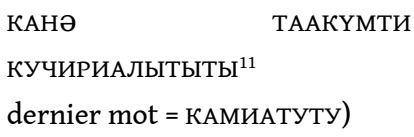 & $\begin{array}{l}\text { Combien d'attelages tiendra-t-il ? (Combien de kilomètres y a-t-il } \\
\text { depuis Hatanga) }\end{array}$ \\
\hline АБАМУНТУ КОБТУАЙ, & les jeunes filles d'Avam, \\
\hline КОБТУАЙ НЕРЫХИАНХЫ & il court après les filles \\
\hline КОЙКИ" МАГИТИТҮ ${ }^{12}$ & depuis Hatanga. \\
\hline
\end{tabular}



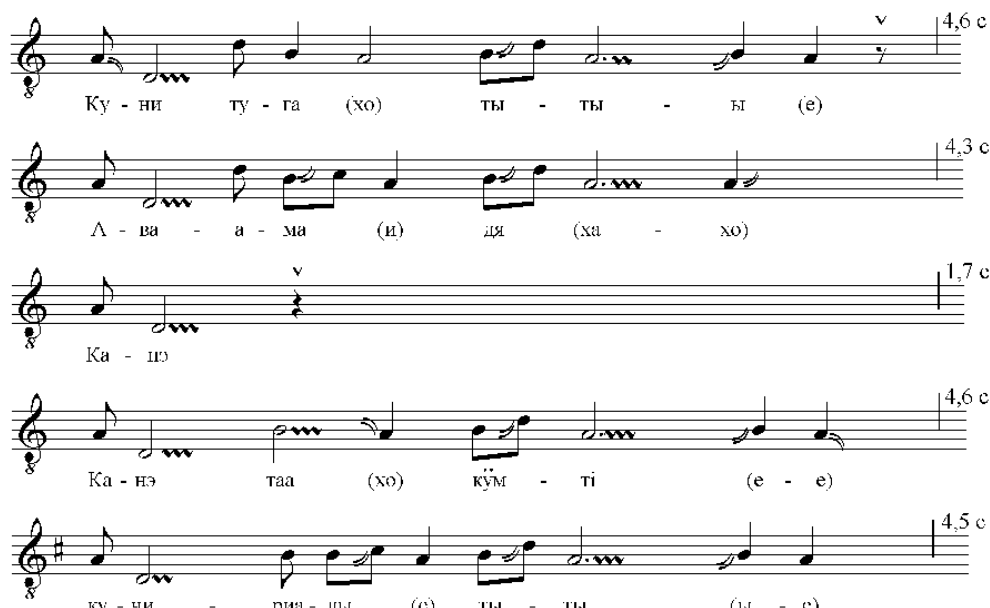

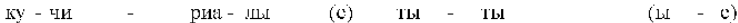
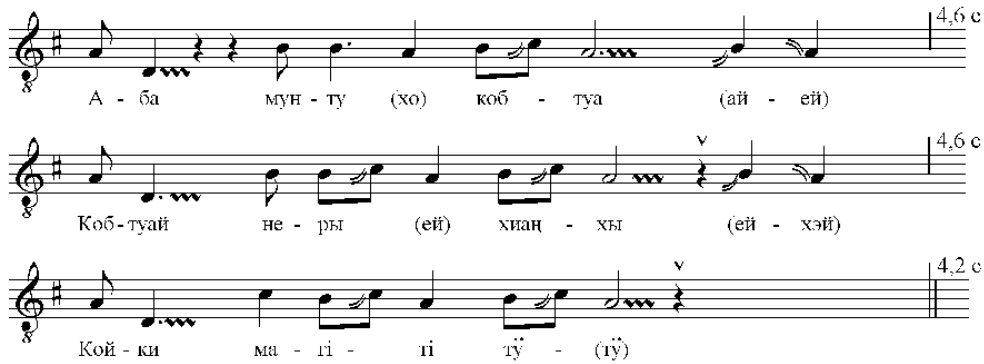

\section{Exemple 6}

\section{Berceuse}

Chantée par Valentina Bintaleevna Kosterkina

Enregistrement 1990 Village de Voločanka.
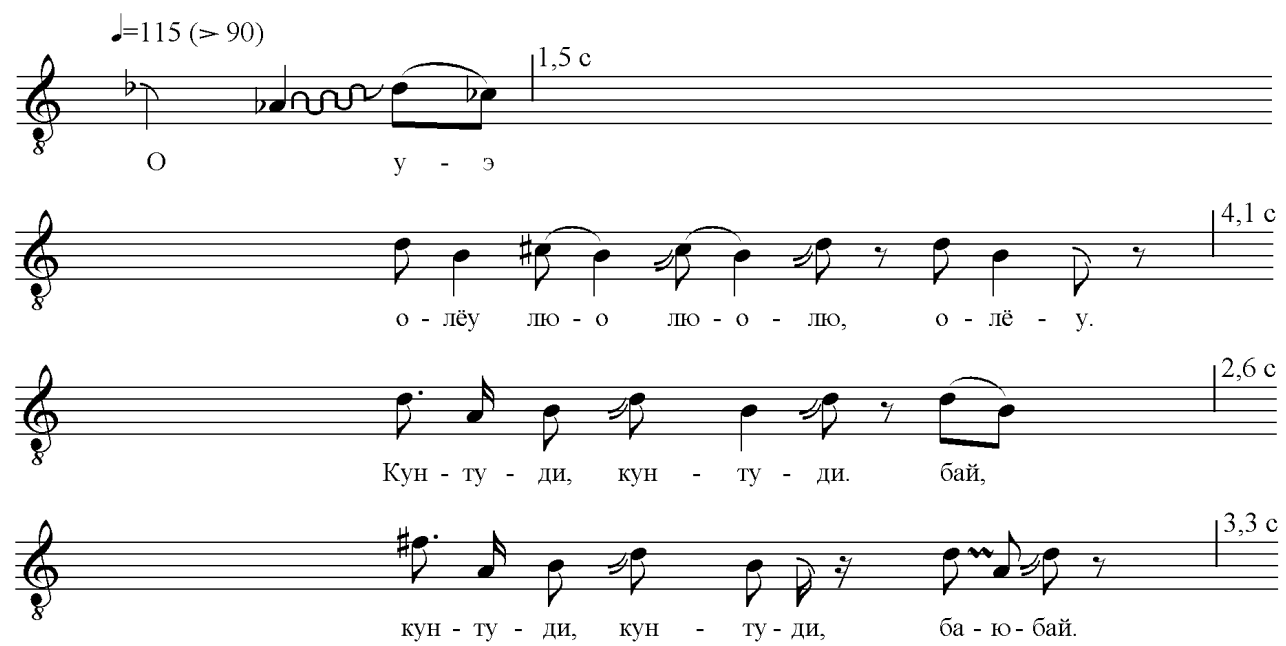

\section{NOTES}

1. En russe : ОАО «ГМК «НОРИЛЬСКИЙ НИКЕЛЬ».

2. En nganassan : КЭЙНГЭЙРСЯ 
3. En nganassan : БАЛЫ.

4. En nganassan : ХОАНГКУТУО БАЛЫ.

5. En nganassan : НюО БАЛЫ

6. En nganassan : НГАЗА БАЛЫ.

7. En nganassan : СИТАБЫ БАЛЫ.

8. Toutes les transcriptions musicales ont été réalisées par l'auteur de cet article et informatisées par Lija Kardaševskaja

о. хоАлә 'КАмни' - les pierres qui roulent symbolisent la demande en mariage, qui se passe par dialogue.

1. кәБәәмә ТАA 'mon renne, ma part' - symbolise la jeune fille désirée.

2. НАМтә БИНу"күчу - les bois repliés représentent ce qu'on dit de la jeune fille.

3. койкү" МАЁㄱ" САНкУ - l'évocation d'une clochette d'église fait référence à la famille chamanique de la jeune fille.

4. Formé d'après le mot НУТАДю - 'un membre de la famille' (mot à mot : " fortune »). Sans doute est-il question ice de la famille proche.

5. Le mot НЕБсәмА"курәку est formé à partir de нЕБсәБты"әگ̆Ы - 'il a caressé la tête'. Quand il est question de flancs, il est fait référence au manteau en fourrure que porte la jeune fille (et pas à une partie de son corps). Le caractère « uni » des flancs du manteau signifie que celui-ci a été cousu admirablement avec des peaux semblables, ce qui est tout à l'avantage de la jeune fille, et de sa grande habileté dans la confection des vêtements.

6. мыәрәН formé à partir de мыәрту няАГәә’- 'joliment habillé, de belle apparence'(valable aussi bien pour un homme que pour une femme).

7. «Pourquoi vous êtes-vous rassemblés autour de moi»- veut dire qu'autour du nouveau-né (ou du bébé) se sont rassemblées trop de personnes, curieuses, venues pour le voir. La mère, mettant en paroles ses pensées, fait délicatement observer que ce n'est pas forcément souhaitable, et qu'à ce moment-là trop de personnes fatiguent l'enfant.

8. L'évocation légère $d u$ "chef du komsomol » présent au moment où la chanson est chantée vise à déplacer l'attention sur autre chose que l'enfant.

9. « МәймәдЕодю кәлсуйчиты »(məjmədeodju kəlsujčity) - déformation des mots «МӘЙМӘЗЕЕЗУ кәРСУЙЧИТЫ» (məjməzeezu kərsujčity). Cette déformation est une imitation de la prononciation possible de l'enfant quand il commence à parler. Les insertions de ce type dans les chants d'enfant sont très fréquentes, elles donnent à ce genre sa spécificité et font passer le sentiment d'un amour tendre à l'encontre de l'enfant.

10. Kuni - noms raccourci de Kunjangku Porbin (ou encore Horbi, comme le prononcent les Nganassanes orientaux) - le garçon dont il est question dans la chanson.

11. Le mot кучириАлытыты (kučirialytyty) ne se rencontre que dans les chants kejnirska (kengejrsja)

12. койкү" МАこ̌ə” (KojkY mažə) - ancienne appellation de Hatanga. 


\section{RÉSUMÉS}

Cet article présente de nouveaux matériaux sur le folklore musical des Nganassans. Les Nganassans sont un petit peuple dont la langue fait partie du groupe samoyède des langues ouraliennes. Ils vivent dans la péninsule du Tajmyr. Différents genres constituent la riche tradition musicale nganassane : des chants métaphoriques, personnels, enfantins, des berceuses. Dans cet article, j'analyse des échantillons des différents genres, en présentant les textes et les transcriptions musicales. Je réfléchirai aussi sur l'état actuel de ces genres et je présenterai aussi des recommandations pour les préserver.

This article presents new materials about Nganassan songs. The Nganassan are a small people whose language belong to the Samoyed group of the Uralic languages. They live in the Taymyr peninsula. Their rich musical tradition is represented by different genres : metaphoric, personal, drinking, children songs as well as lullabies. In this article I analyse some samples of songs belonging to these genres, which are published with the both words and musical transcription. The article assesses the present state of these genres and give some recommendations.

СТАТЬЯ ПРЕДСТАВЛЯЕТ НОВЫЕ МАТЕРИАЛЫ ПО МУЗЫКАЛЬНО-ПЕСЕННОМУ ФОЛЬКЛОРУ НГАНАСАН, КОТОРЫЕ БЫЛИ ОПУБЛИКОВАНЫ В КНИГЕ «ПЕВЦЫ И ПЕСНИ АВАМСКОЙ ТУНДРЫ» (НОРИЛЬСК, 2014). НГАНАСАНЫ ЯВЛЯЮТСЯ МАЛОЧИСЛЕННЫМ НАРОДОМ, ПО ЯЗЫКУ ПРИНАДЛЕЖАТ К САМОДИЙСКОЙ ГРУППЕ УРАЛЬСКОЙ ЯЗЫКОВОЙ СЕМЬИ. ЖИВУТ НГАНАСАНЫ НА ПОЛУОСТРОВЕ ТАЙМЫР. БОГАТАЯ ПЕСЕННАЯ ТРАДИЦИЯ НГАНАСАН ПРЕДСТАВЛЕНА ЖАНРАМИ ИНОСКАЗАТЕЛЬНЫХ, ЛИЧНЫХ, ЗАСТОЛЬНЫХ, ДЕТСКИХ ПЕСЕН, КОЛЫБЕЛЬНЫХ УКАЧИВАНИЙ. В СТАТЬЕ АНАЛИЗИРУЮТСЯ КОНКРЕТНЫЕ ОБРАЗЦЫ ПЕСЕН РАЗНЫХ ЖАНРОВ, РАЗБИРАЮТСЯ ПЕСЕННЫЕ ТЕКСТЫ И НОТНЫЕ ТРАНСКРИПЦИИ. ОЦЕНИВАЕТСЯ СОВРЕМЕННОЕ СОСТОЯНИЕ ПЕСЕННЫХ ЖАНРОВ НГАНАСАНСКОГО ФОЛЬКЛОРА, ДАЮТСЯ РЕКОМЕНДАЦИИ ПО ИХ СОХРАНЕНИЮ.

\section{INDEX}

Mots-clés : chants, tradition musicale, genres musicaux, chants métaphoriques, chants personnels, chants d'enfants, berceuses

Thèmes : ethnomusicologie

nomsmotscles Nganassans

motscleset laul, muusikapärimus, muusikalised žanrid, metafoorilised laulud, isikulaulud, lastelaulud, hällilaulud

motsclesru ПЕСНИ, МУЗЫКАЛЬНЫЙ ФОЛЬКЛОР, МУЗЫКАЛЬНЫе ЖАНРЫ, ИНОСКАЗАТЕЛЬНЫЕ ПЕСНИ, ЛИЧНЫЕ ПЕСНИ, ДЕТСКИЕ ПЕСНИ, КОЛЫБЕЛЬНЫЕ ПЕСНИ

Index géographique : Dudinka, Fédération de Russie, Khatanga, Noril'sk, Taïmyr (presqu'île de), toundra d'Avam, Ust'-Avam, Voločanka

Index chronologique : XXIe siècle

Keywords : Songs, Musical Tradition, Musical Genres, Metaphoric Songs, Personal Songs, Children Songs, Lullabies 